\title{
Revisão sistemática das contribuições de Malba Tahan para a Educação Matemática (2014-2017)
}

\author{
Geraldo Eustáquio Moreira \\ Janaína Mendes Pereira da Silva \\ Paulo Vinícius Pereira de Lima
}

\begin{abstract}
Resumo: 0 artigo se propõe estudar as contribuições de Malba Tahan para a Educação Matemática, de forma a descobrir as principais pesquisas publicadas no período de 2014 a 2017, levantando as contribuições didáticas e a historigrafia do autor. $O$ objetivo é analisar as produções científicas acerca dos estudos, vida e obras de Júlio César de Melo e Souza (Malba Tahan). Para este fim, a escolha da metodologia foi a revisão sistemática, a partir de levantamento bibliográfico de teses, dissertações e artigos qualificados sobre a temática, realizada em quatro etapas: 1) busca por descritores no Portal CAPES, no Google Acadêmico, no repositório de teses e dissertações e no Scielo; 2) seleção e organização por importância, data e tipologia do trabalho; 3) adequação ao tema proposto e aos descritores; 4) análise, estudo e detalhamento do material selecionado. As buscas foram realizadas utilizando cinco descritores específicos sobre o assunto para auxílio e relevância, considerando a data da publicação, a tipologia do trabalho e sua adequação ao tema. Na revisão, observamos que o professor Malba Tahan desperta o interesse do meio acadêmico, literário e histórico, que aponta sua contribuição para a Educação Matemática.
\end{abstract}

Palavras-chave: Revisão sistemática. Malba Tahan. Contribuições. Educação Matemática.

\section{Systematic review of Malba Tahan's contributions to Mathematics Education (2014-2017)}

Abstract: The article presents a study related to the contributions of Malba Tahan, by raising the didactic contributions and the historigraphy of the author in regards to mathematics education, the authors looked at the main research published from 2014 to 2017.

Geraldo Eustáquio Moreira

Doutor em Educação Matemática (PUC-

SP). Professor do Programa de PósGraduação em Educação da Universidade de Brasília (UnB). Distrito Federal, Brasil. $\triangle$ geust2007@gmail.com

Janaína Mendes Pereira da Silva

Mestranda em Educação pela Universidade de Brasília (UnB). Distrito Federal, Brasil. $\square$ janamendesps@gmail.com

Paulo Vinícius Pereira de Lima Mestrando em Educação pela Universidade de Brasília (UnB). Distrito Federal, Brasil. $\bowtie$ paulovinicius@gmail.com

Recebido em 18/01/2019

Aceito em 20/02/2019

Publicado em 01/09/2019
The objective was to analyze scientific production related to studies, life and works of Júlio César de Melo e Souza (Malba Tahan). For this purpose, a systematized bibliographical review was carried out using the theses, dissertations and qualified articles on the subject, and was carried out in four stages: 1) search for descriptors in CAPES Portal, in Google Academic, and in the repository of theses and dissertations and in Scielo; 2) selection and organization by importance, date and typology; 3) adequacy to proposed themes and descriptors; and 4) analysis, study and detailing of the selected material. The searches were carried out using five specific descriptors on the subject for help and relevance, considering the date of publication, the typology of the work and its adequacy to the theme. In the review, we note that Professor Malba Tahan arouses the interest in academic, literary and historical environments which point out his contribution to mathematics education.

Keywords: Systematic review. Malba Tahan. Contributions. Mathematics Education.

\section{Revisión sistemática de las contribuciones de Malba Tahan a la Educación Matemática (2014-2017)}

Resumen: El artículo se propone estudiar las contribuciones de Malba Tahan a la Educación Matemática, de forma a descubrir las principales investigaciones publicadas en el período de 2014 a 2017, levantando 
las contribuciones didácticas y la historigrafía del autor. El objetivo es analizar las producciones científicas acerca de los estudios, vida y obras de Júlio César de Melo y Souza (Malba Tahan). Para este fin, la elección de la metodología fue la revisión sistemática. Se hizo una revisión bibliográfica sistematizada en las tesis, disertaciones y artículos calificados sobre la temática, realizada en cuatro etapas: 1) búsqueda por descriptores en el Portal CAPES, en Google Académico, en el repositorio de tesis y disertaciones y en el Scielo; 2) selección y organización por importancia, fecha y tipología del trabajo; 3) adecuación al tema propuesto ya los descriptores; 4) análisis, estudio y detalle del material seleccionado. Las búsquedas se realizaron utilizando cinco descriptores específicos sobre el tema para ayuda y relevancia, considerando la fecha de la publicación, la tipología del trabajo y su adecuación al tema. En la revisión, observamos que el Profesor Malba Tahan despierta el interés del medio académico, literario e histórico, que apuntan su contribución a la Educación Matemática.

Palabras clave: Revisión sistemática. Malba Tahan. Aportes. Educación Matemática.

\section{Introdução}

Este artigo traz reflexões sobre um importante colaborador da Educação Matemática. Trata-se de um estudo proveniente da disciplina Tópicos de Educação Matemática ofertada no segundo semestre de 2017, cursada no Programa de Pós-Graduação em Educação, da Faculdade de Educação da Universidade de Brasília.

Sendo este resultado de uma pesquisa com abordagens qualitativa e exploratória, tipificado em uma revisão sistemática, há variadas perspectivas a serem desbravadas. Para olhar o que é narrado e explicado sobre um professor, sua vida intelectual e profissional, bem como sua produção bibliográfica e suas redes de relações, para, então, começar a tratar do texto que se quer ler e compreender em uma perspectiva historiográfica: é o que faremos aqui com Malba Tahan, nome adotado pelo professor de Matemática Júlio César de Mello e Souza.

A revisão sistemática é uma proposta metodológica que identifica os estudos sobre um tema determinado, aplica métodos explícitos e sistematizados de busca para uma avaliação e/ou validade de estudos, define algumas perguntas de pesquisa e, a partir destas, define o arcabouço teórico bem como o levantamento de informações capazes ou não de respondê-las. Assim, segue a questão norteadora deste artigo: Os estudos sobre a Malba Tahan e sua relação com a Educação Matemática são relevantes?

Assim, fazer uma revisão sistemática das contribuições de Malba Tahan para a Educação Matemática torna-se o principal objetivo ao analisar as produções científicas acerca dos estudos, vida e obras desse professor de Matemática.

Cabe destacar que a "revisão sistemática de produções científicas nos permite analisar temas já estudados, além da identificação da necessidade de evidenciar determinados estudos científicos, podendo inclusive, auxiliar em investigações futuras" e, para além disso, possibilita a 
utilização de fontes de dados da "literatura já existente sobre o tema abordado", conforme orientam Silva et al. (2016, p. 1-2).

\section{Malba Tahan: elementos de sua vida e obra}

Júlio César de Mello e Souza, ou Malba Tahan, nasceu em 6 de maio de 1895; era carioca, natural do Rio de Janeiro, tendo passado sua infância na cidade de Queluz (SP). De família pobre, pais professores, teve oito irmãos.

Júlio César de Melo e Souza, o quinto dos nove filhos de Seu João de Deus de Mello e Souza e de Dona Carolina de Mello e Souza, nasceu no Rio de Janeiro, em 06 de maio de 1895. Ele gostava de frequentar reuniões e contar histórias com os amigos, histórias com muitos personagens com vários nomes esquisitos como: Mardukbarian, Protocholósck, Orônsio, entre outros, todos ligados no contexto criado da sua cabeça. Com uma infância tranquila, uma das particularidades, quando criança, era ser um colecionador de sapos [...]. (SANTOS, 2016, p. 17)

Formou-se em Engenharia Civil pela Escola Nacional de Engenharia, porém nunca exerceu a profissão. Sua carreira como professor teve início em 1913, no Colégio Pedro II. Antes de atuar como educador matemático, Júlio César de Mello e Souza foi professor das disciplinas Geografia; Física e História.

Começou a lecionar no próprio Colégio Pedro II, depois na Escola Normal. A princípio foi professor de História, Geografia e Física. Mais tarde, optou pela Matemática, por meio da qual sua atuação alcançaria maior destaque. (BIANI e LORENZATO, 2017, p. 836)

Além de professor de Matemática do Colégio Pedro II, foi professor catedrático da Faculdade de Filosofia Ciências e Letras (FFCL) da Universidade do Brasil, atual Universidade Federal do Rio de Janeiro (UFRJ), na cidade do Rio de Janeiro, onde criou metodologias para tornar a matéria mais interessante e de fácil assimilação pelos alunos. Assim, ele passou a ditar paradigmas educacionais para todo o país.

Foi durante o Curso Colegial que Júlio César fez a opção pela carreira do magistério. Saindo do Colégio Pedro II, cursou a Escola Normal e obteve o diploma que 0 habilitava a ser professor primário. De acordo com Siqueira Filho (2008), cursou também a Escola Politécnica, pela qual se formou engenheiro, porém nunca exerceu a profissão. Para ele era mais importante ser professor do que engenheiro, mas 0 diploma de engenheiro o habilitava a ser professor de matemática. (BIANI e LORENZATO, 2017, p. 836)

Conforme Lorenzato (2015), quando jovem, o professor chegou a publicar seu próprio folhetim manuscrito intitulado "Erre", com 25 publicações. Foi professor de Matemática desde 0 
ensino básico até o nível universitário. Aos 23 anos criou dois personagens, um chamado R. V. Slade, professor nova-iorquino, e outro intitulado professor Breno de Alencar Bianco, tradutor. Foi uma forma que descobriu para publicar seus contos nos jornais, sob pseudônimo estrangeiro. Passou a estudar a cultura árabe e, em 1925, criou outro pseudônimo, Ali lezid Izz-Eduim Ibn Salim Malba Tahan, ou simplesmente Malba Tahan. No estilo dos contos árabes, ele passou a contar as proezas matemáticas do calculista persa Beremiz Samir, personagem principal de seu livro mais conhecido O homem que calculava, publicado em 1938.

À procura de novos cenários, Júlio César passou a estudar a cultura árabe, estudou 0 islã, leu o Alcorão e o Talmude. Durante sete anos, chegou também a ter aulas particulares sobre o desenvolvimento árabe. Com a conclusão do trabalho, procurou 0 jornalista Irineu Marinho, diretor do jornal "A NOITE", o jornal mais lido do Brasil, atualmente denominada de Rede Globo de televisão. Júlio César foi recebido por ele, em sua residência, em Santa Tereza-RJ, o qual disse que pretendia surpreender 0 Brasil, com a criação de um escritor árabe junto com os contos orientais educativos escritos pelo professor Júlio César. Foi nesse encontro que criaram o personagem Malba Tahan. (SANTOS, 2016, p. 20)

Júlio César de Melo e Sousa publicou 120 livros, dos quais, 51 referenciados à Matemática. O homem que calculava é seu maior sucesso, alçando voo, inclusive, internacionalmente, com diversas traduções.

\begin{abstract}
A obra $\mathrm{O}$ homem que calculava tornou-se referência em contar histórias sobre o mundo da Matemática, sobre as tradições árabes e muitas outras temáticas ali envolvidas. No entanto, mesmo diante de tamanho reconhecimento, Júlio César de Mello e Souza, nomeadamente Malba Tahan, nunca chegou a viajar ou conhecer os locais tão bem representados em suas obras. Malba Tahan teve diversas produções traduzidas em várias línguas, possuía uma capacidade tremenda ao criar e inventar autores e personagens, com narrativas exóticas. (SOUSA e MOREIRA, 2018, p. 297)
\end{abstract}

Júlio César fez um curso na Escola Dramática Municipal, na então capital do país, Rio de Janeiro, em 1915, não para ser ator, mas para utilizar a dramaturgia como recurso didático em suas aulas. Para Biani e Lorenzato (2017), o matemático procurava ser um bom docente, para isso buscava estratégias e recursos diferentes de ensino.

Entres suas muitas funções, foi educador, escritor, ator, contador de histórias, editor, jornalista, arquivista, político e crítico preocupado com a Educação Matemática, em especial 0 ensino e a aprendizagem em Matemática. Com uma vida profissional tida como lúdica, em 50 anos de atividade literária e educacional, suas experiências, indissociáveis de sua vida profissional e de sua ação como educador/escritor ou escritor/educador, destacam-se sob dois aspectos: o seu engajamento no ensino de Matemática e suas concepções práticas e lúdicas que contribuem com a história da Educação Matemática. 
Segundo Souza e Moreira (2018, p. 295),

Ao disseminar questões didático-metodológicas inovadoras para o ensino e a aprendizagem da Matemática, criando e disseminando estratégias eficazes, Júlio César de Mello e Souza, na contramão do que se apresentava (não era considerado um bom aluno e afirmava que não gostava da didática dos docentes, pois achava cansativas as exposições orais e considerava os professores de Matemática torturadores), tornava possível e descomplicada a arte de ensinar e aprender Matemática.

Biani e Lorenzato (2017) relatam que o professor Júlio César se casou aos 30 anos de idade com Nair Marques da Costa, ex-aluna da Escola Normal, com quem teve três filhos. 0 presidente Getúlio Vargas autorizou o uso dos dois nomes, Júlio César de Melo e Sousa e Malba Tahan, na mesma carteira de identidade. Faleceu em Recife (Pernambuco), no dia 18 de junho de 1974, vítima de um ataque cardíaco e foi sepultado no Rio de Janeiro.

Tabela 1: Temas privilegiados por Júlio César de Mello e Souza em sua produção intelectual

\begin{tabular}{ccc}
\hline Tema & $\begin{array}{c}\text { Número aproximado } \\
\text { de obras }\end{array}$ & $\begin{array}{c}\text { Arco do Tempo das } \\
\text { Publicações }\end{array}$ \\
\hline Contos & 51 & $1925-1974$ \\
\hline Novela & 6 & $1935-1970$ \\
\hline Romance & 2 & 1954 \\
\hline Livro didático & 22 & $1930-1969$ \\
\hline
\end{tabular}

Fonte: Informações extraídas do site https://www.malbatahan.com.br

Reconhecido por suas obras, recebeu diversos títulos, como citam Pires e Apolinário (2017):

Suas obras the renderam reconhecimento nacional, sendo ele agraciado com diversos títulos: cidadão sírio (honorário), cidadão honorário de Ubá (MG), cidadão de Queluz (SP) e da cidade de Itaocara (RJ); e também membro da Academia Carioca de Letras, da Associação Brasileira de Imprensa, da Associação Amazonense de Imprensa, da Sociedade Brasileira de Autores Teatrais, da Associação Brasileira de Educação, entre outros. (p. 41)

Com seus métodos, Júlio César de Melo e Sousa conseguiu protagonizar e revolucionar o ensino da época, "[...] no entanto foi muito criticado e contestado pelos seus colegas de trabalho que eram tradicionalistas" (PIRES e APOLINÁRIO, 2017, p. 41). Por tamanha notoriedade de seu grande personagem, que constava em sua identificação, ele conseguiu validar seu pseudônimo. 
Seria pelo pseudônimo Malba Tahan que Júlio César de Mello e Souza ficaria mundialmente conhecido e famoso. Lorenzato (2015) explica que em 1952, por decreto do então Presidente da República Getúlio Vargas, o pseudônimo foi anexado ao seu nome, passando a constar em sua carteira de identidade [...]. (BIANI E LORENZATO, 2017, p. 836)

No Brasil, foi atribuído ao dia 6 de maio, dia de seu nascimento, o Dia da Matemática, fato que eternizou a sua contribuição para a Educação Matemática no Brasil.

\section{Malba Tahan e a Educação Matemática}

Muitas ideias pedagógicas movimentaram o início do século XX, mediante a contribuição de algumas correntes filosóficas, que realçavam a postura do estudante na construção do seu conhecimento. Nas décadas em que Júlio César de Mello e Souza viveu e lecionou, o ensino e a aprendizagem da Matemática se caracterizavam por uma pedagogia tradicional, e esses processos se dava por meio de transmissão e memorização. Para a assimilação do conteúdo, eram necessárias "muitas definições e fórmulas, rigorosas demonstrações, exercícios com cálculos imensos, o que induzia os alunos à memorização de processos e de resultados, qualquer que fosse a série ou a idade" (LORENZATO, 2015, p. 6).

De 1930 até a década de 1970, Júlio César de Mello e Souza, como autor, teve sua maior produção intelectual e elaborou a maioria de suas obras, assinando-as, em sua maioria, como Malba Tahan. Seus livros discorrem sobre Matemática e Didática de Matemática, além de diversos gêneros literários, tais como: romances, novelas, contos orientais, folclore brasileiro, moral religiosa, formação de professores, Geometria Analítica, Trigonometria Hiperbólica, Funções Moduladas. Escreveu em parceria com alguns educadores e matemáticos de sua época, entre eles Irene de Albuquerque, Euclides Roxo, Célia de Moraes, Cecil Thiré e Manoel Jairo Bezerra.

No período de atuação professional na educação, Malba Tahan contribuiu e aplicou algumas de suas concepções no ensino de Matemática, que aparecem de forma mais evidente na Reforma Francisco Campos, na década de 1930, e durante o Movimento da Matemática Moderna (MMM)1, entre 1960 a 1970, sendo que em ambas fases exerceu influências de uma forma marcante na geração de educadores matemáticos.

\footnotetext{
1 Por volta de 1950, o movimento estadunidense MMM foi exportado para diversos países, chegando ao Brasil em 1960, tendo perdurado até meados de 1970. Era um movimento que pretendia aproximar a Matemática trabalhada na educação básica, aquela que deveria ser acessível a todos, à Matemática produzida pelos pesquisadores da área nos centros de investigação, mediante uma "revolucionária" mudança nas propostas curriculares de Matemática (MOREIRA, 2019, p. 51).
} 
Para Costa (2015), foi um educador crítico da didática usual dos cursos de Matemática da primeira metade século $\mathrm{XX}$, tendo contribuído significativamente para o desenvolvimento da pedagogia da Matemática. Ele foi pioneiro em pensar o uso didático da História da Matemática, a utilizar o método heurístico² de ensino, na defesa de um ensino baseado na resolução de problemas, o que vai ao encontro da Educação Matemática.

São muitas as contribuições desse professor de Matemática que, na "contramão" das dificuldades impostas pelo contexto histórico, viveu como alguém que - conforme a epígrafe deste capítulo assegura - teve amor para fazer "pulsar" o ensino e a aprendizagem dessa ciência na vida de todos aqueles que suas ideias alcançaram. (COSTA, 2015, p. 49)

Em suas aulas, Júlio César de Mello e Souza realizou a exploração didática das atividades recreativas e o uso de material concreto, visto que em seu tempo a disciplina não estava vinculada com a realidade. Assim, surgiram suas propostas didáticas para o ensino e a aprendizagem de Matemática. Isso transformou o ensino dessa disciplina em uma Matemática dinâmica e próxima do cotidiano do estudante, que partia do concreto para o abstrato; integrava a língua materna com a linguagem matemática e a Matemática com as demais disciplinas.

Para Pires e Apolinário (2017, p. 42), sua proposta era ensinar Matemática de uma forma diferente, de modo a despertar o interesse do estudante, sendo que "em suas aulas ele trabalhava com estudo dirigido, manipulação de materiais concretos, matemática recreativa, jogos, enigmas, situações do cotidiano e histórias com os conteúdos (muitas vezes inventadas por ele)". Também defendia o uso da metodologia laboratorial para o ensino e a aprendizagem de Matemática, no qual o laboratório de Matemática deveria ser um espaço com materiais didáticos adequados, 0 uso das tecnologias e jogos no ambiente escolar.

\begin{abstract}
Nesse sentido, as propostas e as recomendações de Malba Tahan iam ao encontro da Educação Matemática que ele defendia ser para todos: propiciar que 0 aluno redescubra a Matemática; conceber o erro como algo positivo e normal no processo de aprendizagem; refletir sobre para quem, o quê, para quê e como ensinar Matemática; jogar para aprender ou aprender jogando; montar o Laboratório de Ensino de Matemática (LEM) com materiais didáticos e bibliografia a respeito da construção e do uso do LEM; usar o método heurístico de ensino; utilizar paradoxos, falácias, lendas, desafios, recreações nas aulas de Matemática; apresentar problemas interessantes aos alunos; contar histórias; utilizar a História da Matemática como apoio didático; integrar língua materna com linguagem matemática e integrar Matemática com outras disciplinas. (BIANI e LORENZATO, 2017, p. 825-826)
\end{abstract}

\footnotetext{
2 Heurística é um conjunto de regras e métodos que conduzem à descoberta, à invenção e à resolução de problemas (BUENO, 2009, p. 1).
} 
Se considerarmos o que Moreira (2019, p. 50) vem discutindo acerca das tendências no ensino e aprendizagem da Matemática, é preciso insistir

[...] num movimento educacional que traz a Educação Matemática para perto dos professores que ensinam Matemática na Educação Básica, que deve ser calçada na contextualização do ensino; na boa formação do professor; no respeito à diversidade de estudantes; na inclusão de todos que encontramos na sala de aula da Matemática e na importância de se produzir conhecimentos científicos com caráter pedagógico, social, político e histórico-cultural que estejam à disposição de todos.

Com relação às influências das relações com a Educação Matemática, nas décadas de 1960 e 1970, para Biani e Lorenzato (2017), pode-se destacar suas reflexões sobre o papel da escola quanto à formação de cidadãos críticos; o papel de se educar contribuindo para que 0 estudante alcance não apenas uma melhoria quantitativa, mas qualitativa em seu meio social. Iniciativa essa que lhe deu grande projeção como educador e que garante a certeza de suas contribuições à Educação Matemática no Brasil.

\section{Os caminhos percorridos para a realização da revisão sistemática das obras de Malba} Tahan

Discorrer sobre a vida de Júlio César de Melo e Souza é constatar que, na sua trajetória, perseveraram diversos personagens que conceberam histórias de vidas com importantes contribuições à Educação Matemática, seja pelo seu exercício como professor, seja pelo seu trabalho literário. Investigar as contribuições dessas histórias é gozar de um mundo extremamente deslumbrante e criativo, onde nos colocamos entre fábulas, lendas, romances e novelas, carregando em suas raízes diversos conhecimentos.

Para esta pesquisa considerou-se a revisão sistemática e foi necessário estabelecer critérios de seleção e exclusão de alguns trabalhos, critérios estes que devem ser explícitos no início da pesquisa. Para Kitchenham (2004), ao conjunto de perguntas e critérios de inclusão e exclusão dá-se o nome de protocolo de pesquisa.

Para alcançar o objetivo deste artigo, as buscas das contribuições de Malba Tahan para a Educação Matemática foram sistematicamente organizadas de forma a identificar as principais pesquisas publicadas no período de 2014 a 2017 relativas ao assunto por nós escolhido e quais instituições estão envolvidas nessa temática. O período foi delimitado por considerarmos importante a análise de produções recentes. As buscas foram realizadas utilizando cinco 
descritores específicos sobre o assunto para seu auxílio e relevância, considerando a data da publicação, a tipologia do trabalho e sua adequação ao tema.

Assim, fizemos uma revisão bibliográfica sistematizada em teses, dissertações e artigos sobre a temática, realizada em quatro etapas: 1) busca por descritores no Portal CAPES, no Google Acadêmico, no repositório de teses e dissertações e no Scielo; 2) seleção e organização por importância, data e tipologia do trabalho; 3) adequação ao tema proposto e aos descritores; e 4) análise, estudo e detalhamento do material selecionado.

Similarmente a Moreira e Salla (2018), nosso interesse foi "[...] analisar esses trabalhos e mostrar como são apresentados à comunidade científica e ao público em geral" (p. 122). Nesse sentido,

\footnotetext{
analisamos os dados referentes às pesquisas mencionadas (teses, dissertações e os artigos), tais como ano de publicação, a modalidade de texto científico, o foco das pesquisas e as metodologias utilizadas para a análise dos dados [...] Fizemos 0 esquadrinhamento das palavras-chave nos resumos, construindo uma lista de descritores; procuramos no texto completo a incidência dos descritores dos resumos. (MOREIRA e SALLA, 2018, p. 122).
}

Esses procedimentos se deram quando buscamos os dados que foram apresentados em gráficos, quadros com os autores, ano de publicação, título e síntese do trabalho apresentado.

A revisão sistemática de produções científicas permite-nos analisar temas já estudados, identificar as necessidades de se levantar obras consagradas e evidenciar determinados estudos científicos, então, entendemos que ela pode auxiliar em investigações futuras sobre o tema estudado, porque "[...] este tipo de investigação disponibiliza a apreciação crítica e síntese da informação selecionada através de buscas sistematizadas" (SAMPAIO e MANCINI, 2007, p. 84), tendo como função "analisar também os pontos de vista metodológicos, a fim de que novos aspectos teóricos emerjam e auxiliem na compreensão da realidade" (INGLES, SCHNECKENBERG e GASPARELO, 2014, p. 2).

A seguir, serão apresentados os resultados dessa revisão sistemática.

\section{Resultados da revisão sistemática}

A partir do detalhamento sobre os caminhos percorridos para a realização da revisão sistemática das obras acerca de Malba Tahan, apresentamos os principais resultados. Organizarmos os trabalhos encontrados cronologicamente durante o período de 2014 a 2017 , conforme cinco descritores: "Malba Tahan e Educação Matemática"; "Malba Tahan e Matemática"; 
"Malba Tahan"; "Júlio César de Melo e Educação Matemática" e, finalmente, "Júlio César de Melo e Matemática". Ao final, reduzimos o universo de investigação conforme a relevância, considerando a data da publicação, a tipologia do trabalho e sua adequação ao tema.

Para Ingles, Scheneckenberg e Gasparelo (2014, p. 4), é importante buscar os aspectos qualitativos do material selecionado, uma vez que a "técnica de tratamento de dados de pesquisa, voltada para uma análise objetiva, sistemática e quantitativa do conteúdo" deve ser considerada neste tipo de pesquisa.

A distribuição cronológica das publicações pesquisadas foi relativamente equilibrada, principalmente em 2014 e 2017, conforme nos mostra o Gráfico 1.

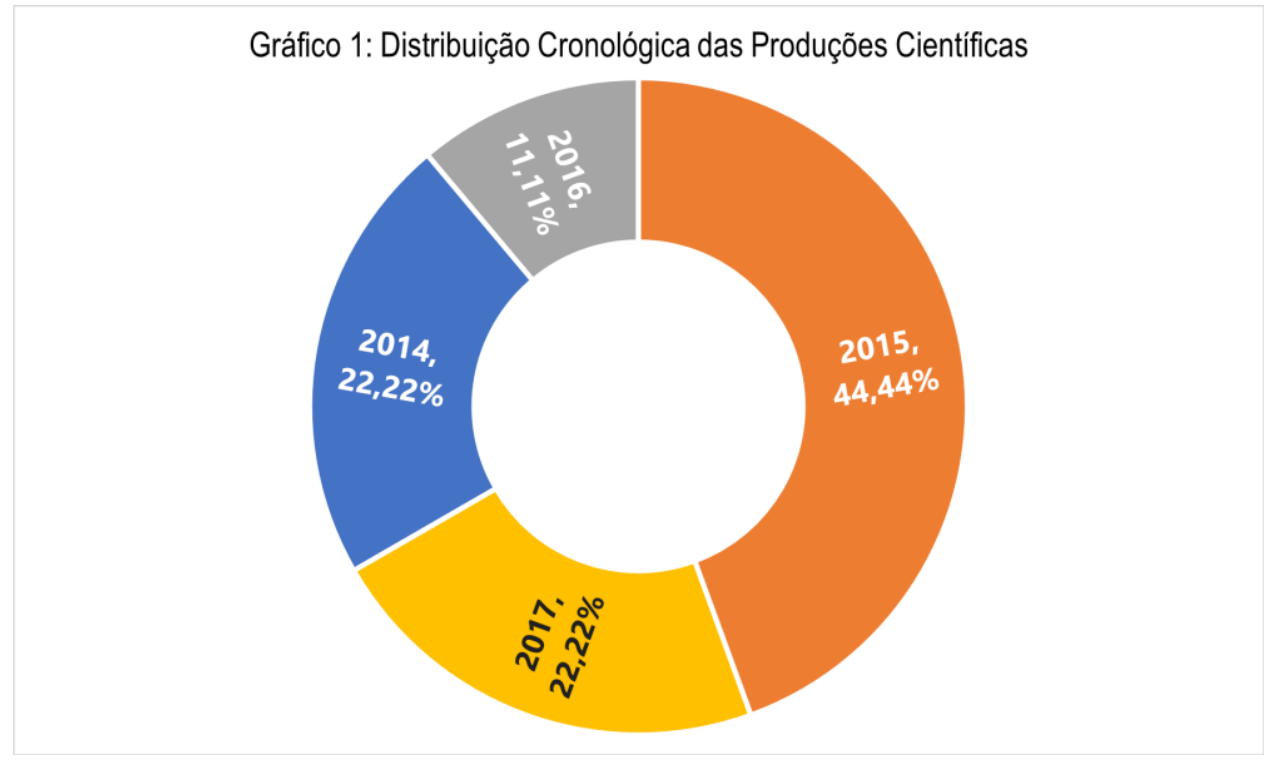

Fonte: Elaboração dos Autores

Em meio ao campo de publicações científicas acerca do tema proposto, as contribuições de Malba Tahan, ao considerarmos aquelas que se aproximam do objeto de análise e ao buscarmos um viés qualitativo, selecionamos nove obras entre artigos e dissertações, conforme mostram os Quadros 1 e 2. Devido ao objeto de investigação, apresentamos no Quadro 1, as seis dissertações encontradas, em âmbito nacional, que foram consideradas mais relevantes.

Quadro 1: Pesquisa em Dissertações/Teses nacionais sobre Malba Tahan e Educação Matemática

\begin{tabular}{|l|l|l|}
\hline \multicolumn{1}{|c|}{ Autor } & Título da publicação & \multicolumn{1}{c|}{ Síntese do trabalho } \\
\hline $\begin{array}{l}\text { Betânia Lopes } \\
\text { Balladares } \\
\text { (UFRGS, 2014) }\end{array}$ & $\begin{array}{l}\text { Malba Tahan, } \\
\text { Matemática e histórias } \\
\text { em quadrinhos: } \\
\text { produção discente de }\end{array}$ & $\begin{array}{l}\text { Trata-se de uma dissertação que apresenta um } \\
\text { estudo sobre a construção de histórias em } \\
\text { quadrinhos (HQs), inspiradas em contos do livro O } \\
\text { homem que calculava (1938), de Malba Tahan, e a } \\
\text { exploração de conceitos matemáticos na leitura } \\
\text { desses contos e na produção dessas histórias por }\end{array}$ \\
\hline
\end{tabular}




\begin{tabular}{|c|c|c|}
\hline Autor & Título da publicação & Síntese do trabalho \\
\hline & $\begin{array}{l}\text { HQs em uma colônia de } \\
\text { pescadores }\end{array}$ & $\begin{array}{l}\text { alunos do Ensino Fundamental. As atividades } \\
\text { foram realizadas com três grupos, totalizando } 13 \\
\text { alunos. Durante o desenvolvimento das atividades, } \\
\text { foram observados o empenho e o progresso dos } \\
\text { alunos na execução das diferentes tarefas que } \\
\text { deram suporte ao estudo, que resultou na produção } \\
\text { escrita discente de três livros de HQs. }\end{array}$ \\
\hline $\begin{array}{l}\text { Clarice Segantini } \\
\text { (UFES, 2015) }\end{array}$ & $\begin{array}{l}\text { Problemas recreativos } \\
\text { na obra O homem que } \\
\text { calculava, de Malba } \\
\text { Tahan, e a resolução de } \\
\text { problemas }\end{array}$ & $\begin{array}{l}\text { Visa investigar e analisar as apropriações e } \\
\text { representações de um grupo de alunos do Ensino } \\
\text { Médio, diante dos problemas extraídos do livro O } \\
\text { homem que calculava (1938), de Malba Tahan, em } \\
\text { um ambiente de resolução de problemas. Trata-se } \\
\text { de um estudo de caso de natureza qualitativa. } \\
\text { Descreve as produções dos alunos nas oficinas de } \\
\text { resolução de problemas e aponta que os problemas } \\
\text { recreativos despertam o interesse, a criatividade, a } \\
\text { imaginação e o uso de estratégias próprias para } \\
\text { resolução, promovem questionamentos, } \\
\text { discussões e o trabalho em grupo entre os alunos. } \\
\text { Evidencia as dificuldades dos alunos em } \\
\text { interpretação e nos cálculos matemáticos. }\end{array}$ \\
\hline $\begin{array}{l}\text { Michelle Aparecida } \\
\text { Silveira (UNESP, } \\
\text { 2015) }\end{array}$ & $\begin{array}{l}\text { A interdisciplinaridade da } \\
\text { obra O Homem que } \\
\text { Calculava aplicada ao } \\
\text { ensino de Matemática }\end{array}$ & $\begin{array}{l}\text { Diante de uma situação educacional, na qual os } \\
\text { alunos demonstram dificuldades em interpretar e } \\
\text { assimilar os conteúdos, elevando o índice de notas } \\
\text { baixas, recuperações e repetências, a investigação } \\
\text { de metodologias alternativas se faz necessária. } \\
\text { Apresentaremos nesse trabalho, formas } \\
\text { diferenciadas de ensino, inspiradas na obra literária } \\
\text { O homem que calculava (1938), escrita por Malba } \\
\text { Tahan, heterônimo do professor Júlio César de } \\
\text { Mello e Souza, com o objetivo de fornecer aos } \\
\text { professores do Ensino Fundamental II uma visão } \\
\text { interdisciplinar dessa obra como ferramenta de } \\
\text { ensino. }\end{array}$ \\
\hline $\begin{array}{l}\text { Leonardo Silva } \\
\text { Costa (UFU, 2015) }\end{array}$ & $\begin{array}{l}\text { Malba Tahan e a revista } \\
\text { Al-Karismi: diálogos e } \\
\text { possibilidades } \\
\text { interdisciplinares com a } \\
\text { história da Educação } \\
\text { Matemática no ensino } \\
\text { fundamental }\end{array}$ & $\begin{array}{l}\text { O trabalho, de natureza qualitativa, tem por objetivo } \\
\text { contribuir para a contextualização da Matemática e } \\
\text { da História da Educação Matemática a partir de } \\
\text { propostas didático-pedagógicas inspiradas pelo } \\
\text { discurso do professor Júlio César de Mello e Souza, } \\
\text { o Malba Tahan na revista Al-Karismi (1946-1951). A } \\
\text { pesquisa propõe um estudo dessa fonte e um } \\
\text { diálogo com as possibilidades didáticas para a } \\
\text { prática docente em matemática na Educação } \\
\text { Básica, envolvendo a História da Educação } \\
\text { Matemática, em uma perspectiva interdisciplinar, e } \\
\text { se utilizando dos instrumentos Fichas de trabalho e } \\
\text { Relatório-Avaliação com alunos do } 8^{\circ} \text { ano do } \\
\text { Ensino Fundamental de uma escola pública. } \\
\text { estudo apontou que os estudantes se envolveram } \\
\text { mais com a prática do professor, relacionando }\end{array}$ \\
\hline
\end{tabular}




\begin{tabular}{|l|l|l|}
\hline \multicolumn{1}{|c|}{ Autor } & Título da publicação & \multicolumn{1}{|c|}{ Síntese do trabalho } \\
\hline \multirow{2}{*}{$\begin{array}{l}\text { Meily Cassemiro } \\
\text { 2016) }\end{array}$} & $\begin{array}{l}\text { Pedagogia de Malba } \\
\text { Tahan na formação de } \\
\text { professores e no ensino- } \\
\text { aprendizagem de } \\
\text { Matemática }\end{array}$ & $\begin{array}{l}\text { alguns termos do discurso tahaniano aos } \\
\text { conhecimentos construídos em sala de aula. A } \\
\text { utilização da História como recurso orienta e } \\
\text { fomenta a compreensão de conteúdos disciplinares, } \\
\text { tangenciando temas interdisciplinares, legitimando } \\
\text { a voz dos estudantes como sujeitos nesse processo } \\
\text { de ensino e aprendizagem e tornando a matemática } \\
\text { divertida, curiosa e prazerosa, bem ao estilo } \\
\text { malbatahanico. }\end{array}$ \\
\hline $\begin{array}{l}\text { O trabalho busca resgatar, aplicar eavaliar a prática } \\
\text { educativa de Júlio César de Mello e Souza, } \\
\text { pseudônimo Malba Tahan, e a interdisciplinaridade } \\
\text { como um possível caminho para iniciar a } \\
\text { compreensão das noções matemáticas na }\end{array}$ \\
$\begin{array}{ll}\text { Educação Infantil, superar as dificuldades do ensino } \\
\text { de Matemática no } 5^{\circ} \text { Ano do Ensino Fundamental I } \\
\text { e promover a formação continuada interna dos (as) } \\
\text { professoras da Educação Infantil e do Ensino } \\
\text { Fundamental I. Envolve uma análise quantitativa e } \\
\text { qualitativa dos dados, em parceria com professores } \\
\text { (as) e estudantes das turmas da Educação Infantil e } \\
\text { do Ensino Fundamental I da escola investigada. Os } \\
\text { resultados mostram que as concepções } \\
\text { malbatahânicas estabelecem uma mobilização } \\
\text { interdisciplinar, no intuito de pensar, elaborar e } \\
\text { decidir quais propostas e intervenções podem ser } \\
\text { aplicadas a partir de um trabalho interativo e } \\
\text { dialógico da Matemática com a Literatura, assim } \\
\text { como destas com as demais áreas do saber. }\end{array}$ \\
\hline
\end{tabular}

Fonte: Elaboração dos Autores

Observa-se no Quadro 1 que as temáticas envolvidas nos trabalhos são variadas e versam sobre resolução de problemas, história da Educação Matemática, interdisciplinaridade e metodologias alternativas.

Verifica-se que a obra O homem que calculava dominou as produções, sendo utilizada de maneira distinta, como, por exemplo, na dissertação A interdisciplinaridade da obra O homem que calculava, aplicada ao ensino de Matemática, na qual se apresenta a dificuldade de se interpretar e resolver situações matemáticas e que traz como alternativa uma perspectiva de ensino fundamentada no trabalho com o livro de Malba Tahan, realizando um trabalho interdisciplinar, que "[...] tornou-se referência em contar histórias sobre o mundo da Matemática, sobre as tradições árabes e muitas outras temáticas ali envolvidas" (SOUZA e MOREIRA, 2018, p. 297). 
Fazenda (2002) ressalta que o termo interdisciplinar nasce na França e na Itália, nos anos de 1960, em detrimento dos movimentos de estudantes que reivindicavam um ensino de caráter social, político e econômico, pois trazia em seu pilar a concepção de que a integração dos conhecimentos poderia resolver os diversos problemas existentes.

Nesse contexto, tem-se a dissertação Malba Tahan, Matemática a e histórias em quadrinhos: produção discente de HQs em uma colônia de pescadores, em que se busca trabalhar com a construção de história em quadrinhos e explorar os conceitos matemáticos trazidos nos contos, resultando na publicação de três livros de HQs.

Se observarmos a quantidade de textos que abordam o disparador temático história - da Educação Matemática, por exemplo -, podemos afirmar que esse é "um recurso didático importante, que possibilita não só a aprendizagem em Matemática, mas, também, auxilia na melhoria da formação dos professores", porque "quando insiro elementos de História da Matemática nas aulas, possibilito a desconstrução da ideia errônea que se tem sobre a Matemática" (MOREIRA, 2019, p. 58), o que deve ser feito cotidianamente!

Por outro lado, o Quadro 2, apresenta as publicações realizadas em periódicos nacionais.

Quadro 2: Pesquisa em periódicos nacionais sobre Malba Tahan e Educação Matemática

\begin{tabular}{|l|l|l|l|}
\hline \multicolumn{1}{|c|}{ Autor } & \multicolumn{1}{|c|}{$\begin{array}{c}\text { Periódico } \\
\text { (Revista), ano }\end{array}$} & \multicolumn{1}{|c|}{$\begin{array}{c}\text { Título da } \\
\text { publicação }\end{array}$} & \multicolumn{1}{c|}{ Síntese do trabalho } \\
\hline $\begin{array}{l}\text { Divino José } \\
\text { Pinto }\end{array}$ & $\begin{array}{l}\text { Via-atlântica, } \\
2014\end{array}$ & $\begin{array}{l}\text { O homem que } \\
\text { calculava, de Malba } \\
\text { Tahan (Um } \\
\text { fenômeno de leitura } \\
\text { literária na infoera) }\end{array}$ & $\begin{array}{l}\text { O artigo traz uma abordagem do } \\
\text { romance O homem que calculava } \\
\text { (1938), de Malba Tahan, que apresenta } \\
\text { características e especificidades que } \\
\text { funcionam como atrativos para a } \\
\text { juventude, num momento de suspensão } \\
\text { de valores e reengenharia das } \\
\text { habilidades ledoras. Cuja competência } \\
\text { leitora está em formação, enfrenta crises } \\
\text { contínuas, e na busca de tal } \\
\text { competência tem à sua disposição } \\
\text { instrumentos de mediação como a } \\
\text { televisão, a internet e outras mídias, que } \\
\text { são verdadeiros facilitadores da } \\
\text { recepção. }\end{array}$ \\
\hline $\begin{array}{l}\text { Sergio } \\
\text { Lorenzato }\end{array}$ & HISTEMAT, & $\begin{array}{l}\text { 2015 } \\
\text { Nacional da } \\
\text { Matemática }\end{array}$ & $\begin{array}{l}\text { A data de 6 de maio é o Dia Nacional da } \\
\text { Matemática, conforme Lei 12 835 } \\
\text { (D.O.U., 26/6/2013), em homenagem ao } \\
\text { professor Júlio César de Mello e Souza, } \\
\text { mais conhecido pelo seu pseudônimo, } \\
\text { Malba Tahan. Ele publicou mais de 70 } \\
\text { obras direcionadas ao ensino de }\end{array}$ \\
\hline
\end{tabular}




\begin{tabular}{|c|c|c|c|}
\hline Autor & $\begin{array}{c}\text { Periódico } \\
\text { (Revista), ano }\end{array}$ & $\begin{array}{l}\text { Título da } \\
\text { publicação }\end{array}$ & Síntese do trabalho \\
\hline & & & $\begin{array}{l}\text { Matemática elementar, entre elas O } \\
\text { homem que calculava (1938) e Didática } \\
\text { da Matemática (1957). Nelas, os } \\
\text { professores podem encontrar muitas } \\
\text { sugestões para facilitar a aprendizagem } \\
\text { da Matemática. }\end{array}$ \\
\hline $\begin{array}{l}\text { Rosana Prado } \\
\text { Biani e Sérgio } \\
\text { Lorenzato }\end{array}$ & $\begin{array}{l}\text { Educação } \\
\text { Temática } \\
\text { Digital, } 2017\end{array}$ & $\begin{array}{l}\text { Malba Tahan + } \\
\text { Matemática = } \\
\text { Malbatemática }\end{array}$ & $\begin{array}{l}\text { O objetivo deste texto é divulgar a vida, } \\
\text { a obra, o legado e a contribuição de } \\
\text { Malba Tahan para a Educação } \\
\text { Matemática. Com isso foi feita uma } \\
\text { exposição intitulada Malbatemática em } \\
\text { homenagem ao professor Júlio César de } \\
\text { Mello e Souza, mais conhecido pelo seu } \\
\text { pseudônimo, Malba Tahan. Trouxe à } \\
\text { mostra objetos, fotos, cartas, } \\
\text { manuscritos e publicações daquele que } \\
\text { é considerado um precursor da } \\
\text { Educação Matemática brasileira, para a } \\
\text { qual sua contribuição foi e ainda é } \\
\text { imensa, justificando a escolha da data } 6 \\
\text { de maio, dia de seu nascimento, como o } \\
\text { Dia Nacional da Matemática. }\end{array}$ \\
\hline $\begin{array}{l}\text { Liceia Alves } \\
\text { Pires e Adrieli } \\
\text { Apolinário }\end{array}$ & $\begin{array}{l}\text { REVEMAT, } \\
2017\end{array}$ & $\begin{array}{l}\text { Malba Tahan, seus } \\
\text { conceitos presentes } \\
\text { na atualidade }\end{array}$ & $\begin{array}{l}\text { O artigo busca relatar uma pesquisa e } \\
\text { uma intervenção pedagógica em uma } \\
\text { sala de apoio a aprendizagem, realizada } \\
\text { com o objetivo de apresentar as ideias } \\
\text { de Malba Tahan e sua prática docente } \\
\text { como um instrumento para ajudar no } \\
\text { trabalho do professor. Para o alcance do } \\
\text { objetivo foi realizou-se um questionário } \\
\text { com professores de Matemática, com o } \\
\text { intuito de verificar quais os } \\
\text { conhecimentos do mesmo sobre o } \\
\text { trabalho de Malba Tahan e na sequência } \\
\text { foram aplicados alguns métodos } \\
\text { propostos pelo autor em uma turma de } \\
\text { Sala de apoio, para verificar se eles são } \\
\text { realmente eficazes. Os resultados } \\
\text { enfatizam o baixo índice de professores } \\
\text { que conhecem as ideias de Malba Tahan } \\
\text { sobre o ensino de Matemática e a } \\
\text { eficácia desses métodos para minimizar } \\
\text { a dificuldade na aprendizagem dos } \\
\text { alunos. }\end{array}$ \\
\hline
\end{tabular}

Fonte: Elaboração dos Autores

Pela análise do Quadro 2, temos um recorte temporal entre 2014 a 2017 dos quatro artigos explorados. As temáticas, nestas publicações, envolvem o relato sobre as contribuições de Julio 
Cézar de Mello e Souza, bem como o seu legado, tratam de suas contribuições para a Educação Matemática e a criação do Dia Nacional da Matemática em homenagem ao autor.

É notório que os "atrativos para a juventude", as "sugestões para facilitar a aprendizagem da Matemática", as "homenagens a Malba Tahan" e a "prática docente de Malba Tahan como um instrumento para ajudar no trabalho do professor", são elementos que enfatizam a importância de se conhecer os principais escritores que impulsionam e motivam o ensino da Matemática. Ora, é "importante deixar claro que, em sala de aula, o professor que ensina Matemática pode se apropriar de elementos de várias tendências que possuem intersecções em uma mesma atividade", de maneira a explorar "o potencial criativo do docente para definir as atividades que se encaixam adequadamente à exploração matemática desejada" na sala de aula (MOREIRA, 2019, p. 61).

Conforme Sandes e Moreira (2018, p. 107), "[...] os interesses dos docentes de Matemática são adquiridos, em sua maioria, na formação inicial e, posteriormente, no convívio social com seus aprendizes". Porém, entendemos que "[...] esses interesses devem ultrapassar a mera reprodução e transmissão de conteúdos matemáticos, cujo resultado é uma atividade interativa da sala de aula de Matemática", porque, "[...] quando o professor da área também se vê em constante formação e investe numa prática docente capaz de ser investigativa" (SANDES e MOREIRA, 2018, p. 107), seja por meio de leitura de artigos e trabalhos como os apresentados aqui, seja pela realização de cursos, é possível ter práticas de ensino assentadas em grandes nomes, como o de Júlio César de Mello e Souza, que buscava o aprimoramento constante de suas atividades.

\section{Considerações}

O aprimoramento nas formas de ensinar e aprender Matemática tem ganhado destaque nas últimas décadas, principalmente a partir de 1980. A formação do professor que ensina Matemática tem acompanhado, em certa medida, essa evolução, assentada, sobretudo, nas Tendências em Educação Matemática, mediante a força que imprime determinada orientação para a atuação docente, cujos impactos oriundos das transformações sociais, pedagógicas e tecnológicas, ditam o fazer pedagógico. Assim, falar nas diversas formas que Júlio César de Mello e Souza escolheu para significar os mecanismos sociais e pedagógicos que regulam as escolhas dos professores que ensinam Matemática, da Educação Infantil à Educação Superior, é buscar formas alternativas de disseminar o conhecimento matemático. 
Estudar Júlio César de Mello e Souza e sua relação com o ensino e a Educação Matemática, ratifica, mais uma vez, um importante educador que fez parte da história do ensino de Matemática, além de atuar em outras áreas, que utilizava suas qualidades literárias na produção de outros tipos de materiais. Concordamos com Souza e Moreira (2018, p. 295), ao afirmarem que "[...] identificar as contribuições e heranças de um educador matemático para a Educação Matemática, com as características do professor Júlio César de Mello e Souza, é um estímulo que nos faz repensar sobre o trabalho do professor na atualidade".

Como exemplo, podemos citar suas colaborações em jornais, rádios e televisão. Neste sentido, ele elaborou textos a respeito do ensino da Matemática e materiais didáticos para serem usados em sala de aula, além de textos literários. Foi ativo na prática docente e, também, como palestrante e ministrador de cursos de curta duração para professores, por conta de sua grande virtude relacionada à área educacional. Há uma estimativa de que sua obra contenha aproximadamente 120 títulos. No Brasil, é um dos primeiros representantes que trabalhou com elementos lúdicos para o ensino matemático.

Nessa análise também se pode destacar que Júlio César de Mello e Souza, em uma perspectiva da Educação Matemática, sempre se discorre sobre sua atuação docente, suas contribuições metodológicas e, de certo, sua produção de livros didáticos que contribuíram para 0 ensino matemático. A presente revisão sistemática resumidamente mostrou, por meio de um estudo bibliográfico, que o professor Malba Tahan desperta o interesse do meio acadêmico e aponta suas influências acadêmicas, literárias e históricas.

Conforme Souza e Moreira (2018, p. 300),

é importante destacar que a partir da década de 1930, ao lado de Euclides Roxo, com quem escreveu o livro Curso de Matemática para o $3^{\circ}$ ano e a coleção Matemática Ginasial, Júlio César de Mello e Souza, comandou uma importante revolução no ensino e aprendizagem do ensino da Matemática, promovendo mudanças curriculares importantes, que refletiram na consolidação da modernização da Matemática.

Por fim, concordamos que "[...] as obras de Malba Tahan nos deixa uma vasta lição de que é possível demonstrar aos alunos que os conhecimentos matemáticos estão envolvidos em diferentes contextos" (SOUZA e MOREIRA, 2018, p. 304), porque a Matemática, em si, proporciona mudanças na forma de ver e conceber o conhecimento, que deve ser inserido na cultura de todos, pois os professores, ao conhecerem diferentes formas de ensinar e aprender Matemática, podem contribuir para a disseminação de práticas de ensino inovadoras, carentes de boa formação e valorização do trabalho pedagógico (MOREIRA e MANRIQUE, 2014). 
Esta pesquisa teve o apoio da Fundação de Apoio à Pesquisa do Distrito Federal (FAP/DF), financiadora do projeto de pesquisa Formação do professor de Matemática na perspectiva da Educação do Campo: formação e prática docente, didáticas específicas de Matemática e acompanhamento da aprendizagem do aluno, também recebeu incentivo do Grupo de Pesquisa Dzeta Investigações em Educação Matemática (DIEM).

\section{Referências}

BALLADARES, Betânia Lopes. Malba Tahan, Matemática a e histórias em quadrinhos: produção discente de HQs em uma colônia de pescadores. 2104. 185f. Dissertação (Mestrado em Ensino de Matemática) - Instituto de Matemática. Universidade Federal do Rio Grande do Sul. Porto Alegre.

BIANI, Rosana Prado; LORENZATO, Sérgio. Malba Tahan + Matemática = Malbatemática. Educação e Temática Digital, Campinas, v. 19, n. 3, p. 822-843, jul./set. 2017.

BUENO, Fabricio. Métodos Heurísticos: teoria e implementações. IFCS: Araguaia, 2009.

COSTA, Leonardo Silva. Malba Tahan e a revista Al-Karismi: diálogos e possibilidades interdisciplinares com a história da Educação Matemática no Ensino Fundamental. 2015. 112f. Dissertação (Mestrado Ensino de Ciências e Matemática) - Instituto de Ciências Exatas e Naturais do Pontal. Universidade Federal de Uberlândia. Ituitaba.

FAZENDA, Ivani Catarina Arantes. Interdisciplinaridade: um projeto em parceria. 5. ed. São Paulo: Loyola, 2002.

INGLES, Maria Amelia, SCHNECKENBERG, Marisa; GASPARELO, Rayane Regina Scheidt. Políticas de educação inclusiva para a formação de professores: uma revisão sistemática. In: $X$ SEMINÁRIO DE PESQUISA EM EDUCAÇÃ̃O DA REGIÃO SUL. Anais da X ANPED SUL. Florianópolis: UDESC, 2014, p. 1-19.

KITCHENHAM, Barbara Ann. Procedures for performing systematic reviews. Reino Unido: Keele University Technical Report, 2004.

LORENZATO, Sérgio. 6 de maio, Dia Nacional da Matemática. Revista de História da Educação Matemática, São Paulo, ano 1, n. 1, p. 4-12, maio 2015.

MOREIRA, Geraldo Eustaquio. Tendências em Educação Matemática com enfoque na atualidade. In: NEVES, Regina da Silva Pina; DÖRR, Raquel Carneiro. (Org.). Formação de professores de Matemática: desafios e perspectivas. Curitiba: Appris, 2019, p. 45-64.

MOREIRA, Geraldo Eustaquio; MANRIQUE, Ana Lúcia. Challenges in Inclusive Mathematics Education: representations by professionals who teach mathematics to students with disabilities. Creative Education, v. 5, n. 7, p. 470-483, 2014.

MOREIRA, Geraldo Eustáquio; SALLA, Helma. O atendimento pedagógico domiciliar de alunos que não podem frequentar fisicamente a escola por motivos de saúde: revisão sistemática das 
investigações realizadas entre 2002 e 2015. Revista Educação Especial, v. 31, n. 60, p. 119-137, jan./abr. 2018.

PINTO, Divino José. O homem que calculava, de Malba Tahan (um fenômeno de leitura literária na infoera). Revista -Via-atlântica, São Paulo, n. 26, p. 231-243, dez. 2014.

PIRES, Liceia Alves; APOLINÁRIO, Adrieli. Malba Tahan, seus conceitos presentes na atualidade. REVEMAT, Florianópolis, v. 12, n. 1, p. 37-50, 2017.

SAMPAIO, Rosana Ferreira; MANCINI, Marisa Cotta. Estudos de revisão sistemática: um guia para síntese criteriosa da evidência científica. Revista Brasileira de Fisioterapia, São Carlos, v. 11, n. 1, p. 83-89, jan./fev. 2007.

SANDES, Joana Pereira; MOREIRA, Geraldo Eustaquio. Educação Matemática e a formação de professores para uma prática docente significativa. Revista @mbienteeducação, v. 11, n. 1, p. 99109, jan./abr. 2018.

SANTOS, Meily Cassemiro. Pedagogia de Malba Tahan na formação de professores e no ensinoaprendizagem de Matemática. 2016. 200f. Dissertação (Mestrado em Projetos Educacionais de Ciências) - Escola de Engenharia de Lorena. Universidade de São Paulo. Lorena.

SEGANTINI, Clarice. Problemas recreativos na obra O homem que calculava, de Malba Tahan, e a resolução de problemas. 2015. 133f. Dissertação (Mestrado em Ensino na Educação Básica) Centro Universitário Norte do Espírito Santo. Universidade Federal do Espírito Santo. São Mateus.

SILVA, Leandro Frederico da; MOREIRA, Geraldo Eustáquio; RIVERA, Andreza Fiorini Perez; RODOVALHO, Maurício Resende; SALLA, Helma; SILVA, Edimar Correia e. Revisão sistemática de produções científicas sobre as práticas inclusivas em Educação Matemática. In: XII ENCONTRO NACIONAL DE EDUCAÇÃO MATEMÁTICA. Anais do XII ENEM: A Educação Matemática na contemporaneidade: desafios e possibilidades. São Paulo: SBEM, 2016, p. 1-11.

SILVEIRA, Michelle Aparecida. A interdisciplinaridade da obra O homem que calculava, aplicada ao ensino de Matemática. 2015. 60f. Dissertação (Mestrado em Matemática em Rede Nacional) Instituto de Biociências, Letras e Ciências Exatas. Universidade Estadual Paulista. São José do Rio Preto.

SOUZA, Aldiléia da Silva; MOREIRA, Geraldo Eustáquio. As influências de Malba Tahan para a Educação Matemática: o legado de um educador à frente de seu tempo. Revista de Educação Matemática, v. 15, n. 19, p. 294-309, maio/ago. 2018. 